\title{
EFFECTIVE TECHNOLOGIES AND TOOLS FOR IMPROVING PROFESSIONALS' AND USERS' COMMUNICATION IN DISABILITY SETTINGS
}

\author{
Encarnación Postigo Pinazo 1
}

\begin{abstract}
Communication with individuals who suffer from a severe intellectual disability is a challenging task for professionals. Technological aids have often been put forward as useful tools. However, most well-known programs are usually designed for disabled people who can perform a certain number of tasks and have some skills for communication. Subjects with severe intellectual disability are seldom the target of research and the training of professionals working with them is hardly properly matched. To fill this gap a group of researchers of the ongoing European project EC+ gather to created friendly communication tools with scientific information and multimodal resources to offer professionals and future professionals (university students) tools, materials, and strategies to communicate with users by means of mobile applications using agile technologies, which will improve communication and hence the quality of staff performance and will reduce stressful situations for both groups, the disabled and workers. The tools were assessed by trainees and professionals in the field of healthcare, education, and community interpreting. The present article focuses on the first and second stages of the EC+ project, which aims to engage professionals and students in seminars, online courses and the completion of questionnaires based on their experience, suggestions, and needs. Research shows that the object of the project is really substantial and hence suggests a further improvement for the work of professionals and therefore is extremely beneficial for the intellectual disabled community. Precise scientific training in several syndromes that hinder communication skills, multimodal tools and the provision of friendly agile technologies draws a promising scenario in this particular field. The results of the questionnaires sent by trainees after the following courses show that they have considerably improved their professional skills and gained self-confidence.
\end{abstract}

UDC Classification: 376; DOI: http://dx.doi.org/10.12955/cbup.v5.1023

Keywords: Severe, intellectual disability, communication, training, professionals, skills

\section{Introduction}

The Enhancing Communication+ project was outlined within one of the of the horizontal priorities of the Erasmus Plus European Scheme:

"Social inclusion: priority will be given to actions that promote in particular through innovative integrated approaches balance and non discrimination in education, training and youth activities. The Programme will support projects that aim to: 1) foster the development of social, civic, intercultural competences, media literacy and critical thinking also combating discrimination, segregation, racism, bullying and violence; 2) enhance the access, participation and learning performance of disadvantaged learners, reducing disparities in learning outcomes. Erasmus+ Guide (2017)"

$\mathrm{EC}+$ addresses the needs of the most disadvantaged learners due to severe intellectual disabilities and fosters ways to empower satisfactory communication both for subjects suffering from syndromes that hinder communication skills and for professionals working with them. Recent research literature such as Light and McNaughton (2014) states that few communication studies are devoted to those who have the most severe communication disabilities and most of the work has been focused on those who, although suffering from any disability, still can handle certain communicative skills. The main outcome will be a mobile application to facilitate this communication. For a satisfactory design of the application are vital not only the collaboration of specialized researchers but also the opinion of professionals within a multidisciplinary scope for our work. This paper will focus on the collaboration of both groups within training activities and the elaboration and optimization of the application.

\section{First stage of research}

Interdisciplinary approach

Our work is based on the collaboration of three main fields or discipline, Medicine, Psychology and Communication in the field of Community Interpreting. Voice interpreters for the intellectually disabled are rarely found within the framework of social policies (Roisko \& Vesala, 2016), professionals (caretakers, nurses, doctors, assistants etc) working with people with severe intellectual disability experience stress since they have not been trained thoroughly with strategies when communication becomes a complex task.

\footnotetext{
${ }^{1}$ Department of Translation and Interpreting, University of Malaga (Spain), epostigo@uma.es
} 
The group of teachers and educators seems to hold the wider expertise in communication. However, as stated above, most of the vast research has been focused on disabled subjects with some abilities. Therefore, teachers also ask for further training. Data for these claims were extracted from a survey, still ongoing, posted in December 2015 and addressed to professionals of the three fields:

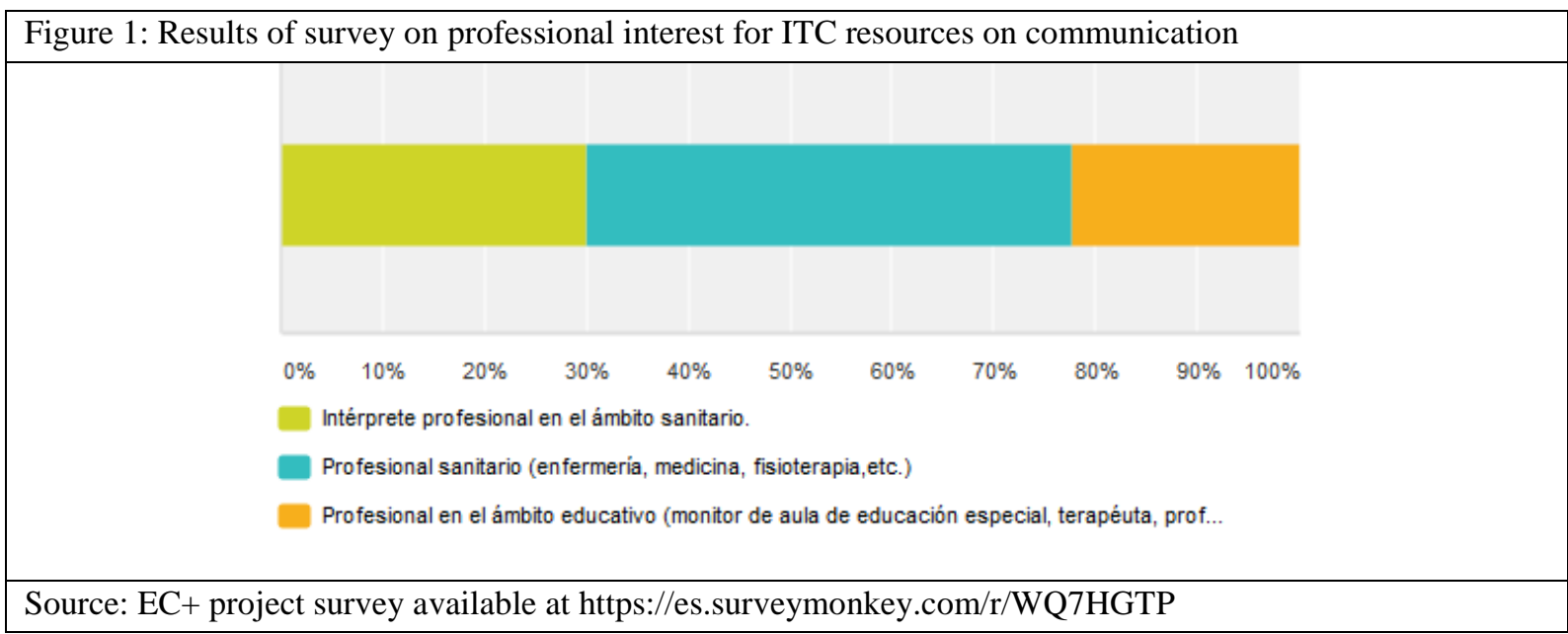

$30 \%$ of the respondents corresponds to professional interpreters in healthcare, $50 \%$ of the answers came from healthcare professionals in fields such as nursing, medicine and physiotherapy and only $20 \%$ belong to the educational field.

Subsequently, our research team considered this prior interest an important factor for our work. Geneticists and doctors provided templates with specific syndromes and features. Those syndromes were selected among the ones that deter communication skills. Psychologists provided documents with intervention guidelines for the same syndromes. A list of words and small phrases was compiled and multimodal resources for communication were hosted in an academic portal for training and the same materials are available using an Android operating system for an app in mobile devices. The app is intended for instant use for both disabled and professionals in their daily life scenarios.

\section{Second stage: training professionals}

As Gray-Stanley et al. (2010) state, staff working with intellectually disabled clients need support networks and interventions to help them manage work stress which according to authors can lead to better follow-through and positive contact with clients. This is also supported in recent studies on the global provision of education, as Czyż's (2016: 307) study states:

Professionalism of the staff is vital for disabled people's care and education. In addition the process of disabled inclusion is related to the skills of bringing adequate support from consideration of readiness of the disabled person and their expectations, as well as increase the professionalism of staff and provide adequate teaching facilities and the friendly environment.

The vital aim of EC+ project is to empower the professionals and the disabled by means of providing both groups the resources and strategies to reduce the emotional impact of complex situations, to enhance professional competence, to provide additional knowledge on disability both in the scientific and technological fields.

For the purpose of training students, professional staff and other stakeholders, the aforementioned set of medical guidelines and intervention in five languages including English is ready to be downloaded both from an academic portal and from the application. Apart from this scientific information participants can find communication documents on sign language and multimodal communication for interpreters and other professional staff.

Different online courses are currently being offered for professionals and students of the aforementioned areas.

The people who are registering belong to the three areas and they match the data percentage of the initial interest survey, although there is at the moment a slight increase in applicants from the educational field. There is also a call for family caretakers who are in charge of severe intellectually disabled subjects to enroll in the online courses. The way the courses have been designed allows the 
training of participants by means of a virtual platform where they find media lectures, questionnaires on Medicine, Psychology and Community Interpreting and Sign Language. They should also need to complete a practical case related to their field of knowledge.

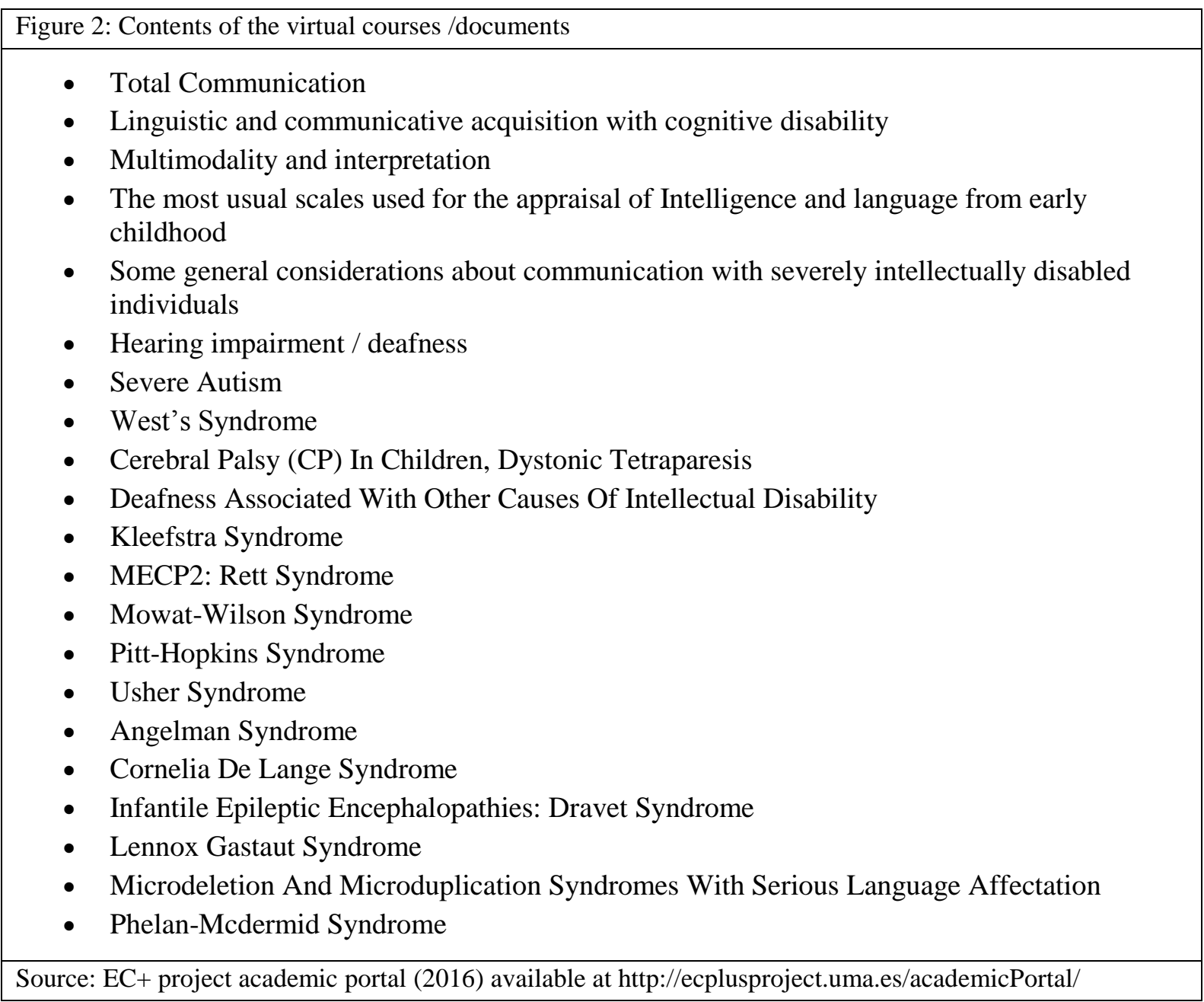

The information listed in Figure 2 is available in five languages (Dutch, Spanish, English, Catalan and German) both in the academic portal as well as in the mobile application that our team has designed. The list of syndromes contains clinical features of those syndromes so that professionals can acknowledge the characteristics of disabled people and possible health risks (Rigola at al, 2016) and also the guidelines for intervention (Brun \& Artigas, 2011). The purpose of the training courses is to enable different professionals from the field of healthcare, education, and interpreting who deal with disabled with interdisciplinary approaches to engage in teamwork in their working environments since they have been provided with the same information and be familiar with the same resources and technological tools. A number of scientific lectures were offered in a face to face previous part of the courses for university students. These lecturers were given by doctors, geneticists, social welfare politicians, healthcare interpreters, rehabilitation researchers, speech therapists, psychologists, ICT engineers, and special education researchers. Lectures were recorded and can be downloaded for the online courses. A set of questions on the lectures are displayed to be completed. Access to the mobile application is available for everyone to test using Google Play application ECPlus published by Francisco Chicano. A set of small surveys is being currently sent to different institutions devoted to the care of intellectually disabled people within the project consortium countries to receive feedback.

All trainees involved in the courses must work with these scientific documents and questionnaires on medicine, intervention and sign language. The questionnaire for interpreters is based on communication strategies, ethic codes and emphasizes multimodal and total communication, which could be in most cases novel information for the latter group of professionals (Parrilla Gómez, 2014), (Pitkäsalo\& Isolahti, 2016). 

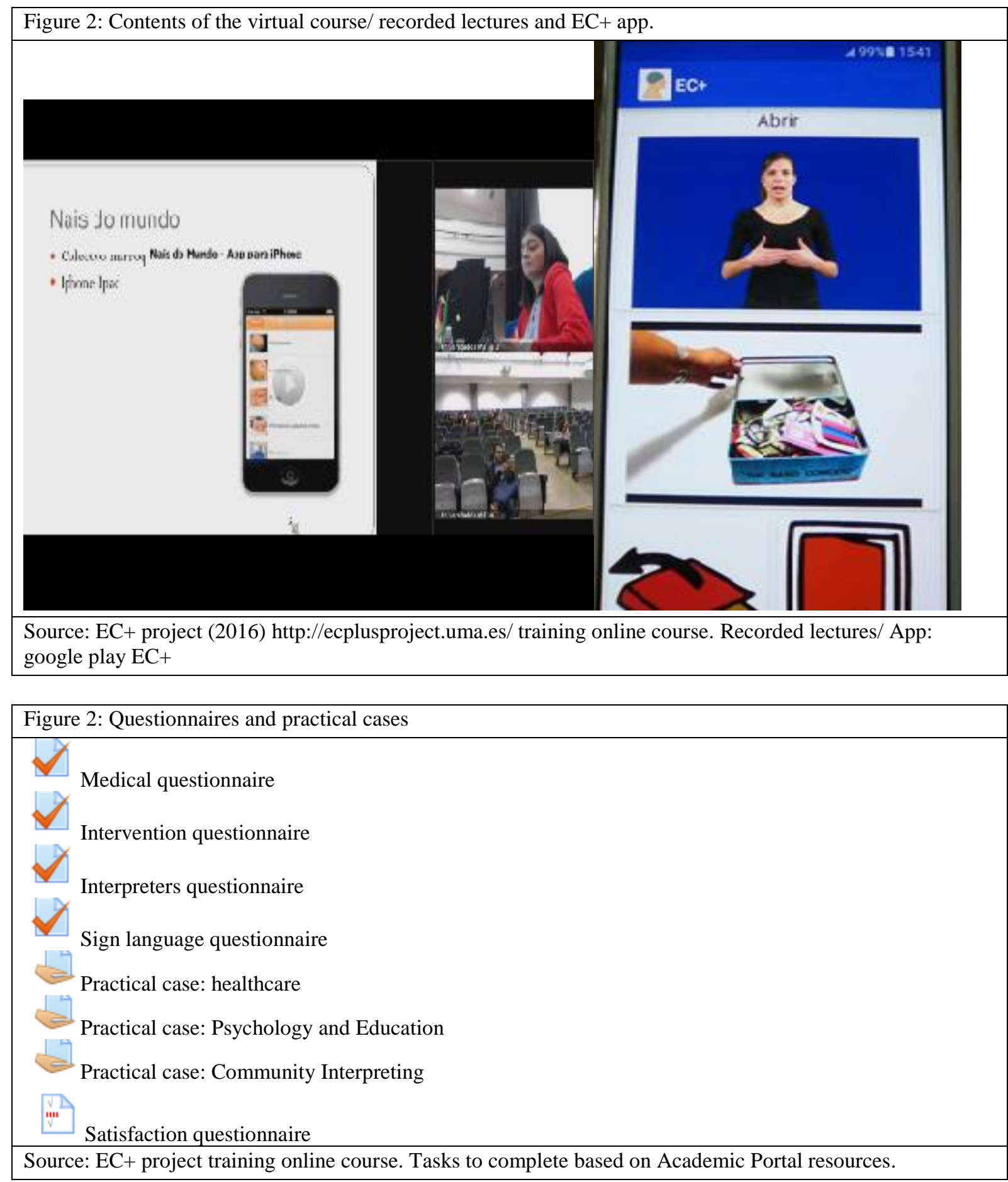

\section{Discussion}

The benefits in this case of methodology used (Choi, 2006) are by far larger than any possible drawback. A follow up of the trainees who are currently engaged in our lifelong training program this academic year would provide data of the real impact of the acquired knowledge. Their feedback after making use of it and of the technological resources in their workplace, in the case of professionals, and within the family, in the case of relatives and professional caretakers, will be really valuable.

The positive impact of the courses in healthcare, education students and professionals is a deep approach to face severe intellectual disabilities. Although clinical or intervention features of disability are included in their university academic syllabus, EC+ project provides an insight on specific clinical features and communication barriers related to subjects suffering from syndromes which seriously hamper communication skills. It is really true that a far more humanistic approach is needed for professional performance (Pino Postigo, 2017). The group of trainee interpreters who are registering in 
our courses in order to receive training to communicate with intellectually disabled subjects for the first time do not have previous knowledge of sign language or total communication approaches. However, their performances when undertaking the different tasks of the courses are absolutely remarkable both for documentation on different resources, which was careful outlined, and for solving practical cases. This is perhaps due to the skills gained in their training or due to their personalities (Nicholson, 2005:126) which make them ICT experts, good communicators who are eager to fullfil documented tasks and ready to provide acurate information on time.

The feedback on the interest and potential of the course and the application is positive up to date, obtaining an average range of 4,5 out 5 in a satisfaction survey after the first online course was finished. Three more courses are ongoing at present.

Assistive technologies should be user-friendly as Cook et al. $(2014,189)$ states so that service providers and the disabled themselves are not reluctant to use them.

The application for mobile devices (Chicano \& Luque, 2016), available for Android and soon for IOS at the moment is being currently assessed by users who agree it is a friendly interface. So far professionals from different fields and those working for disabled day care units or schools have made suggestions for the application to make possible certain actions such as the following:

- Some familiar images such as the ones of relatives should be changed for each particular user so they will be really meaningful.

- Images or video material for housing, food, weather etc. should be changed depending on the culture or nationality.

- Speech therapists suggest that the materials application can be extremely useful for patients suffering aphasia after experiencing cerebral damage.The corpus of words and phrases for the compilation of resources was primarily selected from the Mcarthur Inventory (López Ornat el al, 2005) addressing the needs of people suffering severe or profound intellectual disability and hence complex communication problems. Therefore, some of the professionals when analyzing the application suggest adding more words and phrases, especially those related to their field of work. For instance, healthcare professionals ask for more words on parts of the body, hospital facilities and treatment. The project team will gather responses and study the suggestions from all online courses currently ongoing in the four institutions of the consortium in order to optimize the final version of the application.

\section{Conclusions}

The project EC+ tries to cover a gap in research for one of the most vulnerable group of people who suffer rare diseases and syndromes than hinder communication due to profound intellectual disability to such an extent that most of them need the support for every basic activity of their lives. This goal must be accomplished by multidisciplinary approaches. Our project also aims to empower professionals with scientific information, resources, training and technological tools. In initial stages there was an interest for the initiative through surveys which is now materializing in the training activities and in the assessment of technological tools by students, professionals, and other stakeholders from the three disciplines involved. Participants from the different disciplines who have been following the courses so far consider that this training would be an asset for their future careers and will provide them self-confidence in their performance. Interpreters show remarkable performance completing their training tasks although this particular type of groundwork is quite unusual for them. Another indicator of promising interest from the participants of the training courses is the active involvement and suggestions for resources compilation and the application for mobile devices.

\section{Acknowledgements}

The research has been carried out in the framework of the Erasmus+ project EC+: Reference number: 2015-1- ES01-KA203-015625 "Enhancing communication: research to improve communication for people with special needs and development of ICT resources and tools", coordinated by the University of Malaga with the collaboration of Samsung and the networking support of Tikoteekki. communication and technology Centre (Finnland) Finnish Association on Intellectual and Developmental Disabilities (FAIDD). 


\section{References}

Brun, C. \& Artigas, J. (2011). Síndrome de Angelman:del gen a la conducta. Barcelona:Nau Libres.

Chicano, F. y Luque G. (2017). A Mobile Application and Academic Portal to Support Professionals Working with People Having Severe Intellectual or Developmental Disabilities. In Procedia Social and Behavioral Sciences. 237 (February), 568 575.Retrieved from http://www.sciencedirect.com/science/article/pii/S1877042817301088

Choi, B.C, Pak A.W.( 2006) Multidisciplinarity, interdisciplinarity and transdisciplinarity in health research, services, education and policy: 1. Definitions, objectives, and evidence of effectiveness Clin Invest Med. Dec;29(6),351-64. Retrieved from https://www.ncbi.nlm.nih.gov/pubmed/17330451.

Cook, A. M., \& Polgar, J. M. (2014). Assistive technologies: Principles and practice. Elsevier Health Sciences.

Czyż, A. (2016). Educational and Social Inclusion of Handicapped Children. Polish Experiences. Education Provision to Every One: Comparing Perspectives from Around the World. Sofia: Inverpress, 303-310.

Erasmus+ Guide (2017). Erasmus Plus Program Guide (p. 20). Retrieved March 10, 2017 from:

Gray-Stanley, J. A., Muramatsu, N., Heller, T., Hughes, S., Johnson, T. P., \& Ramirez-Valles, J. (2010). Work stress and depression among direct support professionals: the role of work support and locus of control. Journal of Intellectual Disability Research : JIDR, 54(8), 749-761. http://doi.org/10.1111/j.1365-2788.2010.01303.x $\mathrm{http} / / /$ ec.europa.eu/programmes/erasmus-plus/sites/erasmusplus/files/files/resources/erasmus-plus-programme-guide_en.pdf

Light, J., \& McNaughton, D. (2014). Communicative competence for individuals who require augmentative and alternative communication: A new definition for a new era of communication? Augmentative and Alternative Communication 30 (1), $1-18$.

López-Ornat, S., Gallego, C., Gallo, P., Karousou, A., Mariscal, S., \& Martínez, M. (2005). Inventarios de Desarrollo Comunicativo MacArthur. Manual. Madrid, España: TEA, Ediciones.

Nicholson, N. S. (2005). Personality characteristics of interpreter trainees: The Myers-Briggs Type Indicator (MBTI). The interpreters' newsletter, 13, 109-142. Retrieved December 29, 2011, from http://www.openstarts.units.it

Parrilla Gómez, L. (2014). El reto de una interpretación comunitaria de calidad: buceo en las necesidades formativas y análisis crítico de un corpus de interacción oral en el contexto biosanitario y de servicios sociales español. Doctoral Thesis. University of Malaga.

Pino Postigo, A. (2017). Challenges in Doctor-patient Communication in the Province of Malaga: A Multilingual Crossroads. Procedia Behavioral Sciences. 237, (21 February) 992-997 http://dx.doi.org/10.1016/j.sbspro.2017.02.141. Retrieved from: http://www.sciencedirect.com/science/article/pii/S1877042817301416

Pitkäsalo, E., \& Isolahti, N. (2016). Kääntäminen, tulkkaus ja multimodaalisuus. Menetelmiä monimuotoisten viestin tutkimiseen. Tampereen yliopisto

Rigola, M.A., Baena, N., Catalá, V., Lozano, I. Gabau, E. Guitart, M. Fuster, C. 11.7-Mb (2015). Paracentric Inversion in Chromosome 1q Detected in Prenatal Diagnosis Associated with Familial Intellectual Disability. 146(2):109-14. doi: 10.1159/000437127. Retrieved from https://www.ncbi.nlm.nih.gov/pubmed/26280689?dopt=Abstract.

Roisko, E., Vesala, H. (2016). Granted - not used - Speech Interpreter Services for people with complex communication needs. Helsinki: FAIDD. Retrieved from https://www.isaaconline.org/conference/modules/request.php?module=oc_program\&action=program.php\&p=program

\section{Disclaimer}

The European Commission support for the production of this publication does not constitute an endorsement of the contents which reflects the views only of the authors, and the Commission cannot be held responsible for any use which may be made of the information contained therein 